\title{
石英光ファイバを用いたLD励起中赤外YSGGレーザーの出力特性
}

\author{
大森 繁 \\ テルモ (株) 研究開発本部（テ259-0151 神奈川県足柄上郡中井町井ノ口1500）
}

\section{Diode-Pumped Mid-Infrared YSGG Laser Performance with Silica Optical Fiber}

\author{
Shigeru OMORI \\ R\&D Headquarters, Terumo Corporation, 1500 Inokuchi, Nakai-machi, Ashigarakami-gun, Kanagawa, 259-0151
}

(Received August 9, 2013)

\begin{abstract}
We demonstrated laser operation at $2.8 \mu \mathrm{m}$ in a monolithic Er, Cr: YSGG laser pumped by a laser diode with a silica optical fiber. Under a condition where the pumping beam spot sizes ranged from $90 \mu \mathrm{m}$ to $140 \mu \mathrm{m}$ using a $100-\mu \mathrm{m}$ or a $200-\mu \mathrm{m}$ core diameter fiber, we achieved maximum slope efficiency. During continuous operation, the output power reached $1.09 \mathrm{~W}$ at an incident power of $4.5 \mathrm{~W}$ without any active cooling. When the laser diode is driven by a square wave current where the repetition frequency ranged from $10 \mathrm{~Hz}$ to $10 \mathrm{kHz}$, the average output power of the higher frequency with a lower duty ratio decreases because of the delay of the pulse start timing.
\end{abstract}

Key Words: Solid-state laser, Er,Cr: YSGG, Diode-pump, Optical fiber, Modulation

1. はじめに

波長3 $\mu \mathrm{m}$ 前後の中赤外レーザー光は水に対する吸収 が優れ，生体組織の蒸散に向くことが知られている。こ の波長帯を出力するレーザーデバイスとしては, GaInAsSb-GaSb半導体レーザー ${ }^{1)}$ や非線形光学素子を用 いたパラメトリック発振 ${ }^{2}$ ，あるいは $\mathrm{Cr}^{2+}: \mathrm{ZnSe} / \mathrm{S} フ ァ イ$ バレーザー ${ }^{3)}$ 等が挙げられるが, 実用面ではフラッシュ ランプ励起のErドープ固体レーザーが歯科用を中心とし て応用展開されている ${ }^{4)}$. 固体レーザー結晶は, Er:YAG もしくはEr, Cr:YSGGが用いられるが, この波長帯は石 英材の透過率が低いため, 導光系にはフッ化物ファイバ や中空ファイバ5)が使用される。これに対し, 石英光 ファイバの先端部に固体レーザー結晶を実装し, 半導体 レーザー (LD) を励起光として先端部まで導いて発振さ せる光ファイバ先端発振型固体レーザーが提案されてい る ${ }^{6)}$. 石英光ファイバを用いることで, ビームデリバ リーが容易となり，実用上のメリットは大きいものと考え られる。光ファイバ先端部に実装する固体レーザーヘッ ドのサイズを小さく抑えるためには，チップサイズの レーザー結晶を用い，特別な温度制御手段は無いことが 望ましい。そのためには，用いる固体レーザー結晶の選定 と, 発振効率の良い励起条件を見出すことが重要となる。

LD励起による $3 \mu \mathrm{m}$ 前後の固体レーザー発振は, 1987 年頃より報告され，レーザー結晶としては，これまで Er:YLF ${ }^{7-9)}$, Er:YSGG, Er:GGG, Er:YAG ${ }^{10,11)}$ 等が用いら れてきた。筆者は，フラッシュランプ励起用として入手 が容易なEr, Cr:YSGGを選定し, ワットオーダーの出力
を得ることを目的とし，その発振特性を調べてきた。本 報告では，石英光ファイバ導光のLDで励起する際に高 効率な発振が得られる条件とその限界について実験的検 討を行った結果を述べる。

\section{LDの選定と励起実験系の構成}

Er, Cr:YSGGの励起用LDとしては，レーザー遷移にお ける上準位である ${ }^{4} \mathrm{I}_{11 / 2}$ へのダイレクト励起により高効率 発振が得られる波長として, $970 \mathrm{~nm}$ 前後のマルチモー ドLDを選定し，温度チューニングにより吸収ピーク波 長である波長 $967 \mathrm{~nm}$ 付近に中心波長を調整した。石英 光ファイバ結合が可能なモジュール形態のLDを数種類 選定し，ファイバから出射されるLD光を一旦コリメー トレンズ(メレスグリオ製， $f 25.6 \mathrm{~mm}, N A 0.156)$ で平行 ビームにした後, フォーカスレンズ (10倍の顕微鏡用対 物レンズ，NA 0.25)を用いて集光し，レーザー結晶端面 に結合させた。実験光学系の構成をFig. 1に示す。レー ザー結晶は，Er30\%, Cr2\%ドープのYSGG結晶を用い， 入出射端面をフラット/フラット研磨した後，反射コー ティングを施してモノリシック共振器とした。コーティ ングの仕様は，入射面は波長 $967 \mathrm{~nm}$ に対して透過率 $80 \%$ 以上，波長 $2.8 \mu \mathrm{m}$ に対して反射率 $99.5 \%$ 以上のダイクロ イック多層膜コーティングを施し，出射面は，波長 $2.8 \mu \mathrm{m}$ に対して反射率 $98.2 \%$ のコーティングとした。

レーザー結晶から出射される波長 $2.8 \mu \mathrm{m}$ のレーザー出 力は，励起波長をカットできるフィルタ（HOYA GV-545） を通して光パワーメーターで測定した。 


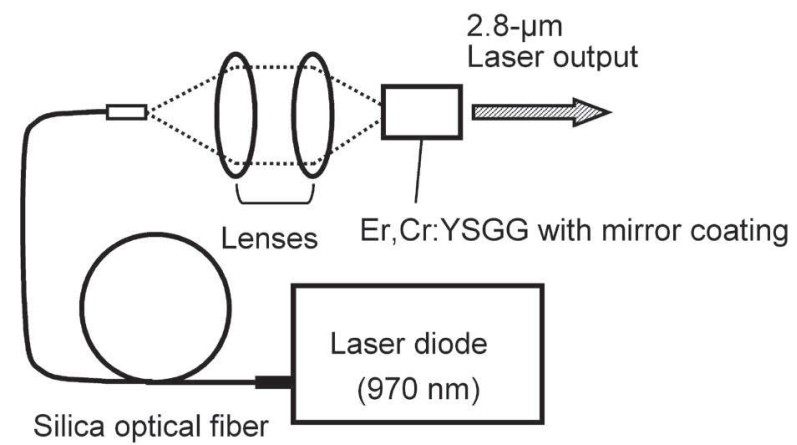

Fig. 1 Schematic representation of the experimental set up for laser diode pump Er, Cr: YSGG monolithic laser.

\section{CW発振特性}

\section{1 励起光スポット径と発振効率}

励起光スポット径が発振効率に及ぼす影響を調べるた め, 出力 $1 \mathrm{~W}$ のシングルエミッタマルチモードLD (エ ミッタ幅 $100 \mu \mathrm{m}$, ファイバレセプタクル付き)にNAが同 一で異なるコア径の石英光ファイバを接続し, 前項で述 ベた実験系を構成した。用いた石英光ファイバは, NA0.22でコア径が $100 \mu \mathrm{m}, 200 \mu \mathrm{m}, 400 \mu \mathrm{m}, 600 \mu \mathrm{m}$ の 種類であり, ビームプロファイラー (PHOTON, inc社 Beam Scan)により測定した集光スポット径は $1 / e^{2}$ 径にて

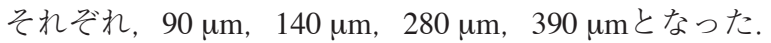
これら4種の集光ビームプロファイル（光軸に沿ったビー ム径変化)をFig. 2に示した。 NAが同一にも関わらず, 相似形となっていない理由は，ファイバ中の伝搬横モー ドがそれぞれ異なっているためと考えられる。

これらのファイバを用いた励起実験では, 結晶サイズ $\phi 6 \mathrm{~mm}$, 厚み $2 \mathrm{~mm}$ のr, Cr:YSGGモノリシック共振器 を真鍮製のホルダに上下から挟み达んで固定し，特別な 冷却は行わず室温で実施した. Fig. 3に, LD光による励 起パワー(フォーカスレンズ後の光パワー)に対する $2.8 \mu \mathrm{m}$ 出力の測定結果を示す. 使用した4種のファイバ について, Fig. 3に示した入出力特性における発振しき

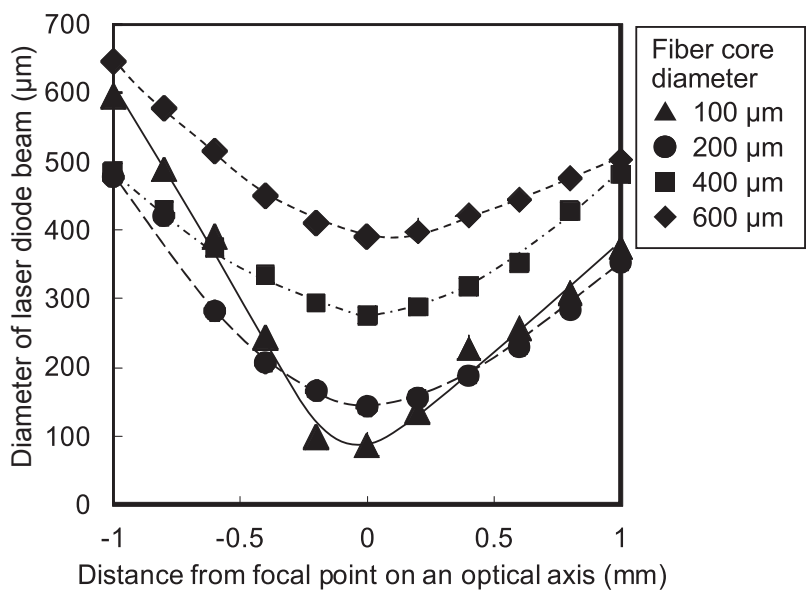

Fig. 2 Laser diode focus beam characteristic as a function of the beam diameter using different optical fibers with core diameter of $100 \mu \mathrm{m}, 200 \mu \mathrm{m}, 400 \mu \mathrm{m}$, and $600 \mu \mathrm{m}$.

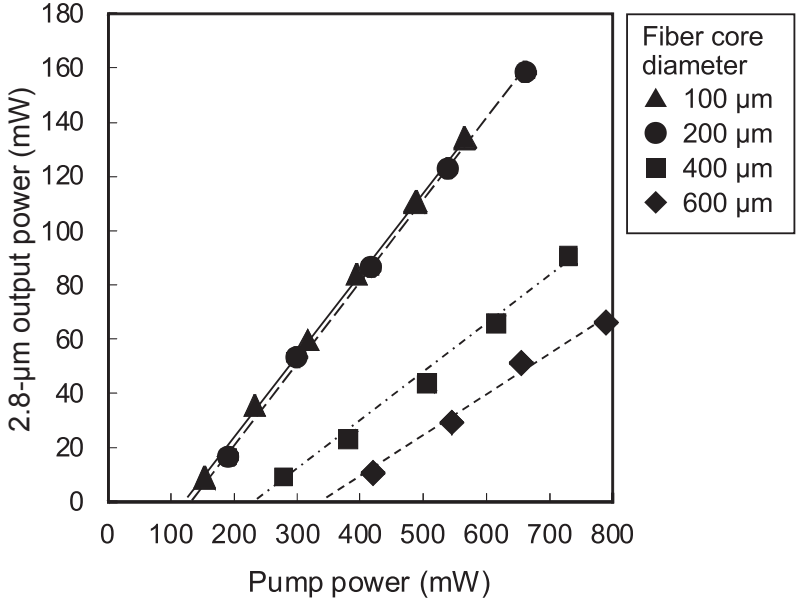

Fig. $32.8-\mu \mathrm{m}$ laser output power as a function of laser diode pump power for different optical fibers with core diameter of $100 \mu \mathrm{m}, 200 \mu \mathrm{m}, 400 \mu \mathrm{m}$, and $600 \mu \mathrm{m}$.

Table 1 Experimental result of 2.8- $\mu \mathrm{m}$ output efficiency (under $1 \mathrm{~W}$ of pump power).

\begin{tabular}{ccc}
\hline $\begin{array}{c}\text { Fiber core } \\
\text { diameter }(\mu \mathrm{m})\end{array}$ & $\begin{array}{c}\text { Threshold power } \\
(\mathrm{mW})\end{array}$ & Slope efficiency $(\%)$ \\
\hline 100 & 119 & 30.1 \\
\hline 200 & 128 & 29.9 \\
\hline 400 & 244 & 18.0 \\
\hline 600 & 345 & 15.3 \\
\hline
\end{tabular}

い值とスロープ効率をTable 1に示した。 光ファイバコア 径100 $\mu \mathrm{m}, 200 \mu \mathrm{m}$ につては，共にスロープ効率30\%, 発振しきい值 $120 \mathrm{~mW}$ 前後となり, コア径 $400 \mu \mathrm{m}$, $600 \mu \mathrm{m}$ ものと比較して高い発振効率が得られてい る.

コア径200 $\mu \mathrm{m}$ で励起した場合における出力レーザー 光のビーム強度プロファイルを結晶端面より $12.5 \mathrm{~mm}$ 位 置で測定した結果をFig. 4 (a) (b) に示した. Fig. 4 (b) に は，ビームプロファイラーを用いてガウシアンフィット させた結果を2次元表示しているが，比較的良い整合が 得られている。広がり角を内挿して求めた出射端面での ビーム径は $110 \mu \mathrm{m}$ とった。 これを $D_{0}$ として, 距離 $z=12.5 \mathrm{~mm}$ 離れた位置におけるビーム径 $D(z)$ を，ガウ シャンビームの場合に成立する式 (1)に当てはめて計算

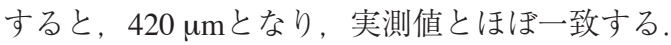

$$
D(z)=D_{0} \sqrt{1+\left(\frac{4 \lambda z}{\pi D_{0}^{2}}\right)^{2}}
$$

以上のことより, この条件においてはTEM ${ }_{00} に$ 近い横 モードが得られているものと考えられる.

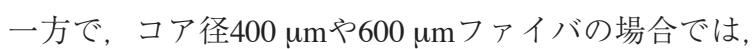
出射端面でのビーム径はコア径200 $\mu \mathrm{m}$ の場合と比較し て大きくなり，また $D(z)$ と $D_{0}$ の関係は式 $(1)$ に適合しな くなる. 励起スポット径が大きくなると, 高次の横モー ドが混合するものと考えられ，Table 1に示した発振しき い值はその影響を受けた結果であると推測される。 
(a)

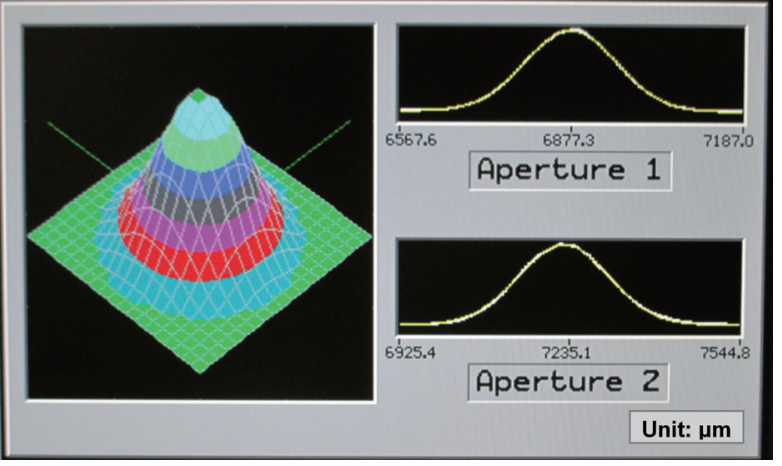

(b)

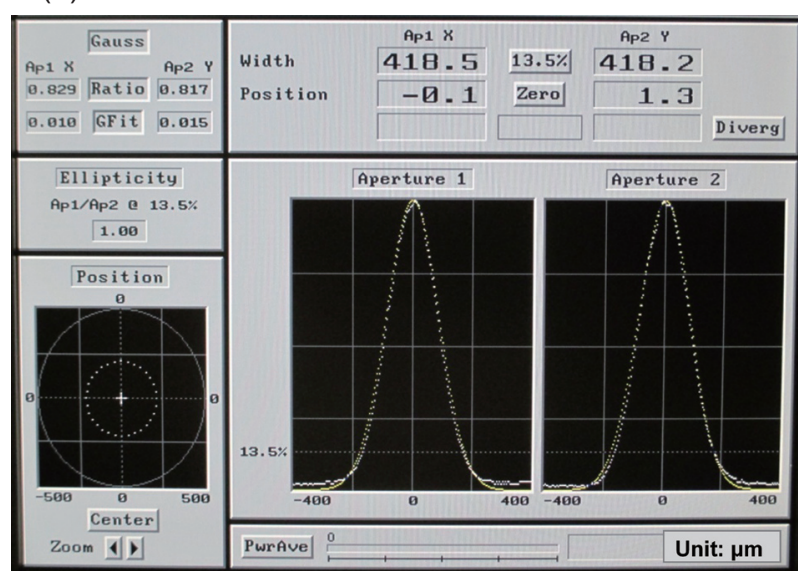

Fig. 4 2.8- $\mu \mathrm{m}$ output laser beam profile using a $200 \mu \mathrm{m}$ core fiber for propagation of pump source. (a):3dimensional plot of a beam. (b):2-dimensional plot of a beam overlaying a Gaussian profile and goodness of fit.

\section{2 出力限界について}

\subsection{1 熱によるレーザー結晶の破損}

Er, Cr:YSGG結晶の熱伝導率は $0.06 \mathrm{~W} \cdot \mathrm{cm}^{-1} \cdot \mathrm{K}^{-1}$ であり， Er:YAGの $0.12 \mathrm{~W} \cdot \mathrm{cm}^{-1} \cdot \mathrm{K}^{-1}$ と比較して $1 / 2$ 以下である。特 に, $\mathrm{Er}$ ドーパント濃度が高い本結晶の場合, 励起端面で は局所での温度上昇が起こりやすいと考えられ，一定以 上の励起パワーに拈いてクラックが入り, 結晶が使用不 能となることを経験している，端面励起の本レーザー構 成に抽は，その出力上限は熱による結晶の破損に よって制限される可能性があると考えられるため, 励起 パワーを上げていき, レーザー発振状態において結晶が 破損する限界点を確認する実験を行った。

励起光源としては, コア径200 $\mu \mathrm{m}$ のファイバ端で最 大8 Wの出力が得られるLDユニットを用いた。レー ザー結晶は, 放熱効果を高めるため, $1.4 \mathrm{~mm}$ 角 (長さ $2 \mathrm{~mm}$ )にカットし, 真鍮製のホルダーヘサーモグリスを 介して固定した。真鍮製ホルダーはステンレスロッドに ネジ止めした上で光学ステージに固定し，温度制御は行 わなかった。

幾つかの結晶を用いて実験した結果，励起パワー $4.6 \mathrm{~W}$ において, 励起開始1分を過ぎた時点で出力がゼロ となり，Fig.5に示したように結晶にクラックが入るも のがあった，また，このような破損が起きなくても，励

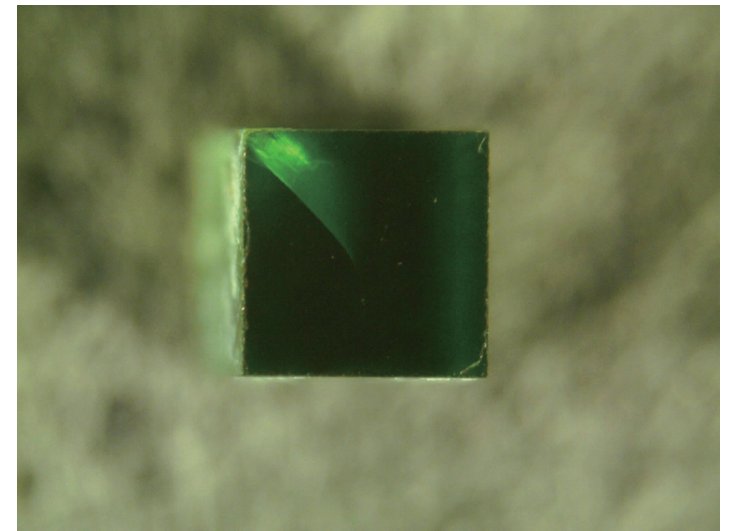

Fig. 5 Er, Cr: YSGG crystal $(1.4 \mathrm{~mm} \times 1.4 \mathrm{~mm} \times 2.0 \mathrm{~mm})$ fractured by the pump power exceeding a limit.

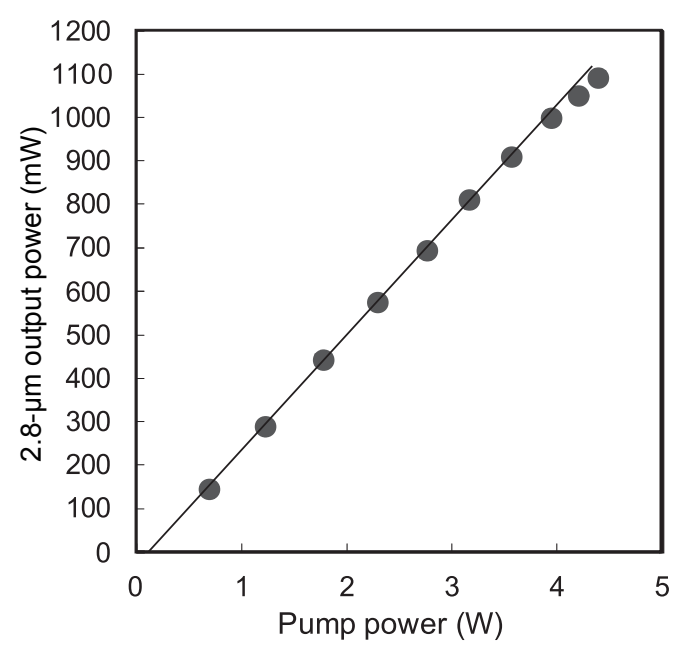

Fig. 6 2.8- $\mu \mathrm{m}$ output power as a function of laser diode pump power during continuous drive using a 200- $\mu \mathrm{m}$ core diameter fiber.

起5 W以上においては出力が飽和する傾向があり，今回 用いた実験系のように，金属性ホルダーへの自然放熱を 前提とした場合には，励起パワーは $4.5 \mathrm{~W}$ 以下に抑える のが実用的と考えられる。

\subsection{2 最適励起位置における入出力特性}

励起パワー上限を $4.5 \mathrm{~W}$ とした時の励起光に対する波 長2.8 $\mu \mathrm{m}$ レーザー出力を測定した。 その際, 励起パワー $3 \mathrm{~W}$ 以上においては, 励起光の結晶入射端面への最適結 合位置 (波長 $2.8 \mu \mathrm{m}$ 出力が最大となる光軸位置) が, 低い パワーで励起した場合と比較して結晶内側へ $0.2 \mathrm{~mm} シ$

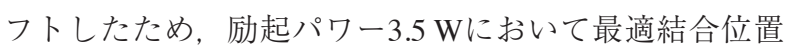
の調整を行い, その位置において入出力特性を測定し た. 結果をFig. 6に示す. $3.5 \mathrm{~W}$ 以上の励起パワーにおい て僅かなスロープ効率の低下が見られたが, $4.5 \mathrm{~W}$ 励起 時において $1.09 \mathrm{~W}$ の波長 $2.8 \mu \mathrm{m}$ 出力が得られた。この出 力は励起開始後2分経過後に $1.05 \mathrm{~W}$ まで低下した後ほぼ 安定した。本実験構成において熱平衡状態に達したもの と考えられる。 


\section{4. 矩形波変調特性}

励起光源であるLDを矩形波変調することにより熱緩 和を図り、レーザー結晶の温度上昇を抑えることは実用 面に扔いて有効な手段と考えられる。

Duty ratio(以下DRとする) $10 \% ， 20 \% ， 30 \% ， 50 \% の$ 矩 形波について, 繰り返し周波数 $10 \mathrm{~Hz}$ から $10 \mathrm{kHz}$ までD 駆動電流を変化させ, 励起レーザー光 (LD光) と波長 $2.8 \mu \mathrm{m} レ ー サ ゙ ー$ 光の平均出力を測定した. 結果を Fig. 7 (a) (b) に示す. 励起光がこれらの周波数領域に扔 いてどのDRに対してもほぼフラットであるのに対し， 波長2.8 um出力光は, DR30\%以下では周波数の増加に 伴って, またDR50\%の場合には $100 \mathrm{~Hz}$ 以上の周波数に おいて出力が低下する結果となった。

周波数応答性が励起光と異なる原因を調べるため, $\mathrm{PbS}$ ディテクタを用いて $\mathrm{Er}, \mathrm{Cr}: \mathrm{YSGG}$ の発振時間波形を 観察した。その結果, DR50\%の場合では, 矩形パルス のピークに到達するまでに $2.1 \mathrm{msec}$ 要し，このため繰り 返し周波数 $200 \mathrm{~Hz}$ (Time Duration: $2.5 \mathrm{msec}$ ) を超える条件

(a)

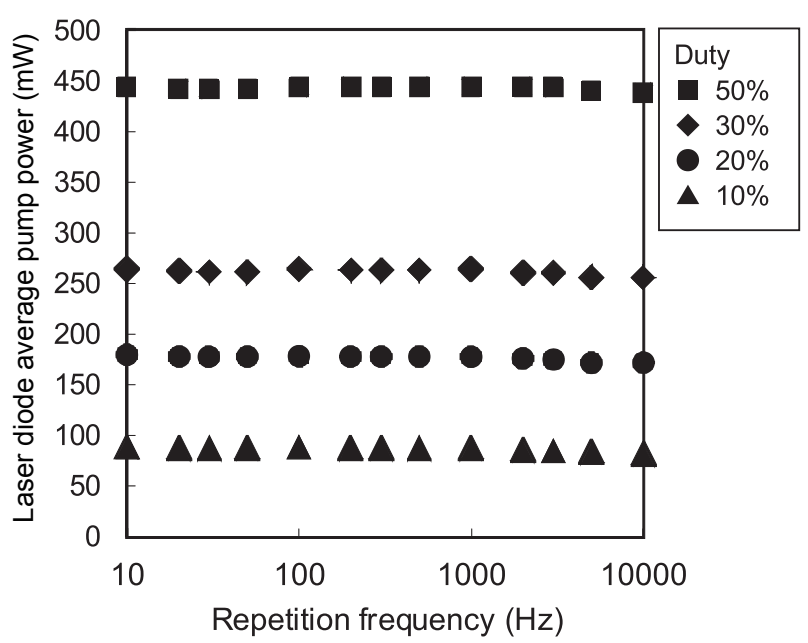

(b)

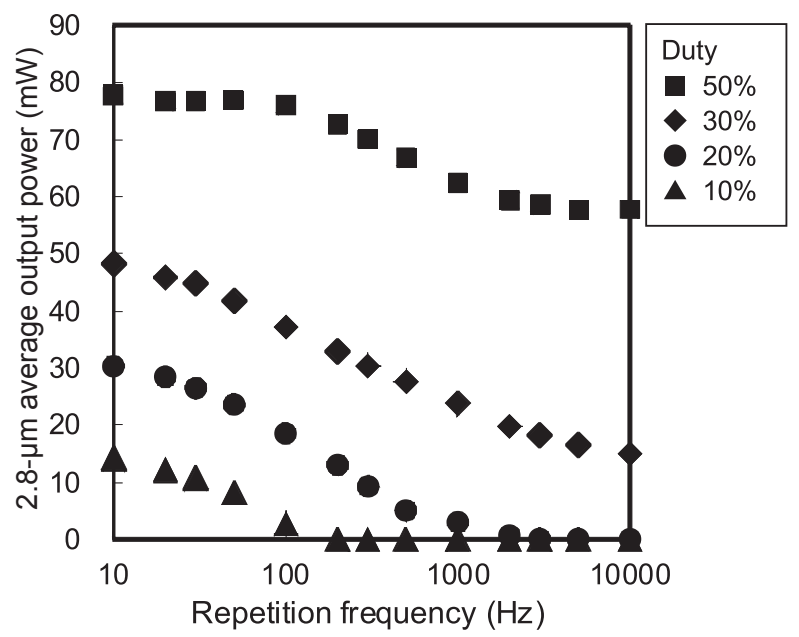

Fig. 7 Average power during square wave pumping where the repetition frequency ranged from $10 \mathrm{~Hz}$ to 10 $\mathrm{kHz}$. (a):laser diode output. (b):2.8- $\mu \mathrm{m}$ output.

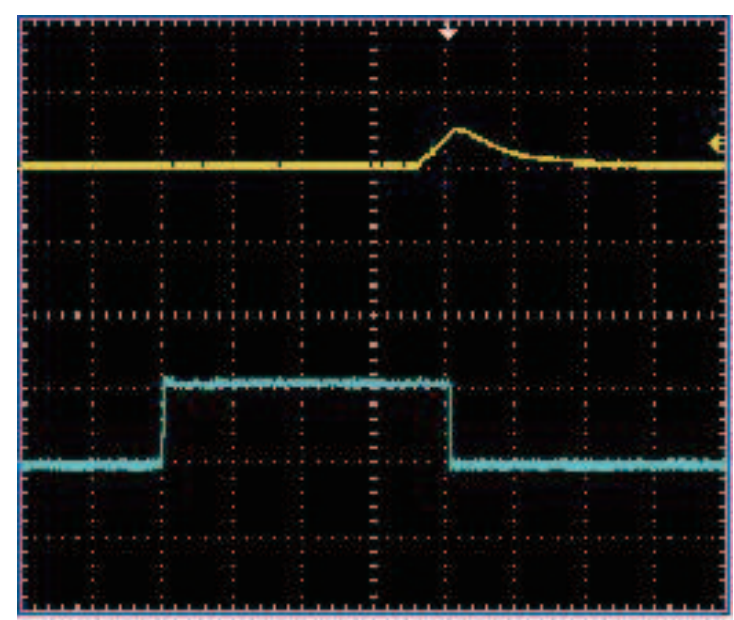

Fig. 8 Output waveform at a $100 \mathrm{~Hz}$ repetition frequency with $10 \%$ duty ratio of square wave current for a laser diode. Upper trace is 2.8 - $\mu \mathrm{m}$ output waveform and lower trace is pumping waveform showing the delay of the output pulse start timing.

では平均出力が低下し，更に $1 \mathrm{kHz}$ 以上では周波数応答 限界に達したものと考えられた。また，パルス間隔が広 い場合では，矩形パルスの入力タイミングと発振の開始 タイミングとが同期せずDelayが観察された。例えば, パルス間隔が9 msecとなる繰り返し $100 \mathrm{~Hz}, \mathrm{DR} 10 \%$ の条

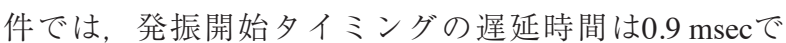
あった(Fig. 8)。矩形パルスのTime Durationがこの遅延 時間以下となる $200 \mathrm{~Hz}, \mathrm{DR} 10 \%$ では発振不能になると 考えられるが, Fig. 7 (b)に示した測定結果でも，この 条件に打ける出力は零となっている.

レーザー結晶における熱緩和を図りながら最大平均出 力を得る目的で矩形波変調を行う場合には，発振時間波 形を考慮する必要がある。

\section{5. まとめ}

光ファイバ先端発振型の波長 $2.8 \mu \mathrm{m}$ 固体レーザー用結 晶として, $\operatorname{Er}(30 \%), \mathrm{Cr}(2 \%)$ ：YSGGを選定し，波長 $970 \mathrm{nmLD}$ 励起光源に用いて発振特性を評価した。コ ア径が異なる石英光ファイバを用いて端面励起した結 果， $100 \mu \mathrm{m}-200 \mu \mathrm{m}$ コア径ファイバを用いて $90 \mu \mathrm{m}-$ $140 \mu \mathrm{m}$ の集光スポットで励起した場合に高い発振効率 が得られ，連続励起による最大出力は，コア径200 $\mu \mathrm{m}$

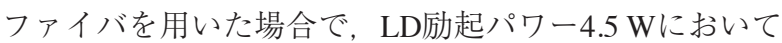
$1.09 \mathrm{~W}$ となった。レーザー結晶に対する能動的な朎却は 不要であり, 光ファイバ先端部への実装形態に適するも のと考えられる.

また，励起LDを矩形波変調した場合では，波長

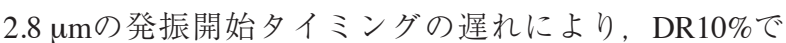
は繰り返し周波数 $200 \mathrm{~Hz}$ 以上で発振困難となった。高い 平均出力を得る場合には，発振時間波形を考慮して変調 条件を設定する必要があると考えられる。 


\section{参考文献}

1) K. Rossner, M. Hummer, T. Lehnhardt, M. Muller, A. Forchel, M. Fischer, and J. Koeth: IEEE Photo. Tech. Lett. 18 (2006) 1424.

2) A. Henderson and R. Stafford: Opt. Express 14 (2006) 767.

3) Xiushan Zhu and Ravi Jain: Opt. Lett. 32 (2007) 2381.

4) 熊崎護：日レ医誌 17 (1996) 1.

5）松浦祐司, 宮城光信：レーザー研究 27 (1999) 173.

6) 大森繁：レーザー学会第289回研究会報告レーザー医学・ 生物学応用, RTM-01-24 (2001) 52 .
7) G. J. Kintz, R. Allen, and L. Esterowitz: Appl. Phys. Lett. 50 (1987) 1553

8) R. C. Stoneman, J.G. Lynn, and L. Esterowitz: IEEE J. Quantum Electron. 28 (1992) 1041.

9) T. Jensen, A. Diening, and G. Huber: Opt. Lett. 21 (1996) 585.

10) Bradley J. Dinerman and Peter F. Moulton: Opt. Lett. 19 (1994) 1143.

11) T. Jensen, V.G. Ostroumov, and G. Huber: in ASSL, eds. B. Chai and S. Payne (OSA Proceedings Series Vol.24, OSA, Washington, 1995) IL4. 